\title{
HUBUNGAN INISIASI MENYUSU DINI TERHADAP LAMANYA PENGELUARAN PLASENTA
}

\section{THE RELATIONSHIP OF EARLY BREASTFEEDING INITIATION TO LONG EXPLOSION OF THE PLACENTA}

\author{
Heri Rosyati ${ }^{1}$, Dina Sulviana Damayanti ${ }^{2}$ \\ 1,2 Program studi Sarjana Kebidanan Fakultas Kedokteran dan Kesehatan \\ Universitas Muhammadiyah Jakarta \\ Email Correspondence: herirosyati@umj.ac.id
}

\begin{abstract}
The Relationship Of Early Breastfeeding Initiation To Long Explosion Of The Placenta. Early initiation of breastfeeding between mother and baby can reduce maternal and infant morbidity and mortality because it is very useful in stimulating the release of oxytocin so that it helps uterine involution and controls bleeding, helps accelerate of placenta expultion, and helps accelerate of breastfeeding. Besides being beneficial for mothers, early initiation of breastfeeding is also very beneficial for newborns because it can avoid hypothermia, and strengthen the bonding attachment between mother and baby. The purpose of this study was to determine the relationship between early breastfeeding initiation and the length of the placenta expulsion process at the Sawah Besar Public Health Center. This type of analitic research with a cross sectional approach. This research is quantitative with a cross sectional approach. The population of this study amounted to 50 respondents with a sample of 33 respondents who gave birth, the sampling technique used a random sampling system. Data collection was carried out using secondary data (September - October 2021), data analysis using the chi square test. The results obtained were 28 respondents who gave birth to mothers who did early initiation of breastfeeding, the length of the placenta expulsion process was $<15$ minutes ( $\mathrm{p}$ value $=0.001$ ) with a value $=0.05$. So it can be concluded that there are significant results between early initiation of breastfeeding and the length of the placenta expulsion process at the Sawah Besar Health Center. Early initiation of breastfeeding is very important and should be carried out in both vaginal and cesarean deliveries, unless the condition of the mother or baby requires further treatment.
\end{abstract}

Keywords : early initiation of breastfeeding, placenta expultion

\begin{abstract}
Abstrak: Hubungan Inisiasi Menyusu Dini Terhadap Lamanya Pengeluaran Plasenta
Proses inisiasi menyusu dini antara ibu dan bayi dapat menurunkan angka morbiditas dan mortalitas ibu dan bayi karena sangat bermanfaat merangsang pengeluaran oksitosin sehingga membantu involusi uterus dan mengendalikan pendarahan, membantu percepatan pelepasan plasenta, serta membentu percepatan pengeluaran ASI. Selain bermanfaat untuk ibu, inisiasi menyusu dini juga sangat bermanfaar bagi bayi karena dapat terhindar dari hipotermi, dan memperkuat bounding attachment ibu dan bayi. Tujuan penelitian ini untuk mengetahui hubungan inisiasi menyusui dini terhadap lamanya proses pengeluaran plasenta di Puskesmas Sawah Besar. Jenis penelitian ini adalah analitik dengan pemdekatan cross sectional. Populasi penelitian ini berjumlah 50 responden dengan jumlah sampel 33 responden ibu bersalin, teknik pengambilan sampel menggunakan sistem random sampling. Pengumpulan data dilakukan dengan menggunakan data sekunder (bulan September - Oktober 2021), analisi data menggunakan uji chi square. Hasil yang diperoleh sebanyak 28 responden ibu bersalin yang dilakukan inisiasi menyusu dini lama proses pengeluaran plasentanya $<15$ menit ( $p$ value $=0,001$ ) dengan nilai $\alpha=0,05$. Maka dapat disimpulkan hasil signifikan antara inisiasi menyusui dini terhadap lamanya proses pengeluaran plasenta di Puskesmas Sawah Besar. Inisiasi menyusu dini sangat penting dan harus dilakukan pada proses persalinan baik normal maupun cesar, terkecuali jika kondisi ibu atau bayi perlu penanganan lebih lanjut.
\end{abstract}

Kata Kunci : inisiasi menyusu dini, pengeluaran plasenta 


\section{Vol 11 No 1 Bulan Januari | Page 144-148}

\section{PENDAHULUAN}

Inisiasi menyusu dini (IMD) adalah memberi kesempatan pada bayi baru lahir untuk menyusu sendiri pada ibunya dalam 1 jam pertama. Caranya dengan meletakkan bayi baru lahir dengan menengkurapkan bayi yang sudah dikeringkan tubuhnya di atas dada ibunya segera setelah persalinan dan memastikan bayi mendapat kontak kulit dengan ibunya, membiarkan bayi merayap menemukan puting susu dan menghisapnya untuk mendapatkan asupan kolostrum (ASI yang pertama kali keluar) (Satriani, 2021).

Manfaat Inisiasi Menyusu Dini (IMD) pada ibu dapat mencegah terjadinya perdarahan karena dengan IMD dapat menghasilkan hormon oksitosin yang dapat berkontraksi pada uterus sehingga plasenta lahir lebih cepat dan dapat mencegah terjadinya retensio plasenta dan perdarahan (Fikawati, S., \& Syafiq, 2014). Bagi bayi IMD sangat bermanfaat karena dapat terhindar dari hipotermi, mencegah infeksi, mencegah diare, menambah angka harapan hidup anak karena dapat mencegah kematian pada neonatus, dan memperkuat bounding attachment ibu dan bayi (Abie and Goshu, 2019).

Menurut Data SDKI pada tahun 2017, angka kematian ibu (AKI) Provinsi DKI Jakarta sejumlah 53/178.982 dari kelahiran hidup, penyebab kematian ibu terbanyak yaitu pendarahan $(30,3 \%)$ (BKKBN, BPS and Kemenkes RI, 2018). Kematian ibu akibat pendarahan. Pendarahan terbanyak terjadi pada kala III akibat lama nya pengeluaran plasenta atau dalam waktu 30 menit plasenta belum lahir dan kala IV persalinan akibat sisa sisa plesenta yang tertinggal dan akibat berkontraksi rahim yang dapat terjadi pendarahan (sarli, 2017).

Terlambatnya IMD juga dapat meningkatkan angka kesakitan dan kematian bayi. Dalam studi yang dilakukan secara systematic review, bayi yang diberi ASI di bawah satu jam pertama kelahiran lebih kecil resiko kematiannya daripada yang diberikan setelah dua jam(Smith et al., 2017). Program pemerintah dalam menekan AKI dan AKB yaitu, Program Maternal and Infant Mortality Meeting (M3) dari tingkat desa sampai tingkat kabupaten, pendampingan ibu hamil resiko tinggi, rumah tunggu kelahiran (RTK). Pelayanan Kesehatan tingkat pratama dalam hal ini Puskesmas juga berperan aktif dalam mewujudkan program ini (Kemenkes, 2021).

Berdasaran survey pendahuluan melalui wawancara dengan bidan Puskesmas Kecamatan Sawah Besar sebagian besar ibu bersalin yang di lakukan IMD pada saat pengeluaran plasenta, waktu yang dibutuhkan dalam batas normal tidak sampai $>15$ menit. Dari hasil studi literatur dan survey awal peneliti tertarik untuk meneliti lebih lanjut tentang inisiasi menyusu dini dengan lama proses pelepasan plasenta.

\section{METODE}

Jenis penelitian yang digunakan adalah analitik dengan pendekatan cross sectional. Penelitian ini berlokasi di Puskesmas Sawah Besar Jakarta Pusat. Penelitian dilaksanakan pada bulan Oktober 2021. Populasi dalam penelitian ini adalah semua ibu bersalin di Puskesmas Sawah Besar Jakarta Pusat pada bulan September - Oktober 2021 yang berjumlah 50 responden. Pengambilan sampel menggunakan teknik sistem random sampling dengan kriteria inklusi dan eksklusi didapatkan jumlah sampel 33 responden. Pengumpulan data pada penelitian menggunakan data sekunder. Melihat dan menelaah data yang sudah ada dalam rekam medis persalinan yang terjadi pada bulan September Oktober 2021 untuk dianalisis dan dipilih sesuai dengan kriteria inklusi dan eksklusi. Setelah data yang dikumpulkan sesuai dengan jumlah sampel yang diteliti, data diolah menggunkan aplikasi 
Vol 11 No 1 Bulan Januari | Page 144-148

software Statistical Kemudian data yang ada ditulis dan dikode sesuai dengan kriteria penelitian. Product and Service Solutions (SPSS) Versi 20 dengan uji chi square.

HASIL

Tabel 1. Distribusi Frekuensi Responden Berdasarkan Umur dan Jumlah Persalinan

\begin{tabular}{lcc}
\hline Variabel & Frekuensi (n) & Persentase (\%) \\
\hline Umur (tahun) & & \\
$19-29$ & 22 & 66.7 \\
$30-40$ & 11 & 33.3 \\
\hline Jumlah & 33 & 100 \\
\hline Persalinan ke & & \\
1 & 8 & 24.2 \\
2 & 16 & 48,5 \\
3 & 6 & 18.2 \\
4 & 3 & 9.1 \\
\hline Jumlah & 33 & 100 \\
\hline
\end{tabular}

Berdasarkan tabel 1 dapat diketahui dari 33 ibu bersalin di Puskesmas Sawah Besar Jakarta Pusat pada bulan September - Oktober 2021 sebanyak 66.7\% ibu bersalin berusia 19 - 29 tahun. Sedangkan sebanyak 33.3\% ibu bersalin berusia 30 - 40 tahun, dan sebanyak $48.5 \%$ adalah persalinan ke-2, 24.2\% persalinan ke-1, 18.2\% persalinan ke-3, dan 9.1\% persalinan ke-4.

Tabel 2. Distribusi Frekuensi Ibu Bersalin Yang Melakukan Inisiasi Menyusui Dini dan Tidak

\begin{tabular}{lcc}
\hline Variabel & Frekuensi (n) & Persentase (\%) \\
\hline Inisiasi Menyusu Dini & & \\
Dilakukan & 28 & 84.8 \\
Tidak dilakukan & 7 & 15.2 \\
\hline Jumlah & 33 & 100 \\
\hline
\end{tabular}

Hasil data pada tabel 2 menunjukkan bahwa dari 33 ibu bersalin sebanyak 28 ibu bersalin (84.8\%) ibu bersalin yang dilakukan inisiasi menyusu dini. Sedangkan 7 ibu bersalin (15.2\%) yang tidak dilakukan inisiasi menyusu dini.

Tabel 3. Hubungan inisiasi menyusu dini dengan lama pengeluaran plasenta

\begin{tabular}{|c|c|c|c|c|c|c|c|c|}
\hline \multirow{3}{*}{$\begin{array}{l}\text { Insiasi } \\
\text { (IMD) }\end{array}$} & \multirow{3}{*}{ Menyusu } & \multirow{3}{*}{ Dini } & \multicolumn{4}{|c|}{ Lama Pengeluaran Plasenta } & \multirow{3}{*}{ pValue } & \multirow{3}{*}{ Mean waktu } \\
\hline & & & \multicolumn{2}{|c|}{$<15$} & \multicolumn{2}{|c|}{$>15$} & & \\
\hline & & & $\mathbf{N}$ & $\%$ & $\mathbf{N}$ & $\%$ & & \\
\hline Dilakuk & Kan & & 26 & 92.8 & 2 & 7.2 & 0.001 & 5.43 \\
\hline Tidak d & lilakukan & & 1 & 14.3 & 6 & 85.7 & 0.265 & 16.45 \\
\hline
\end{tabular}

Hasil analisis pada tabel 3 menunjukkan bahwa ibu bersalin yang dilakukan inisiasi menyusu dini lama pengeluaran plasenta $92.8 \%<15$ menit dengan rata-rata waktu pengeluaran plasenta adalah 5.43 menit. Sedangkan ibu bersalin yang tidak dilakukan inisiasi menyusu dini lama pengeluaran plasenta $85.7 \%>15$ menit dengan rata-rata waktu pengeluaran plasenta adalah 16.45 menit.

https://ejournal.umpri.ac.id/index.php/JIK $\mid \mathbf{1 4 6}$ 


\section{Vol 11 No 1 Bulan Januari | Page 144-148}

\section{PEMBAHASAN}

Program inisiasi menyusu dini (IMD) sangat perlu dilakukan kepada bayi yang baru lahir untuk mencegah tingginya kematian neonatal. Pada IMD, bayilah yang diharapkan berusaha untuk menyusu. Pada jam pertama, bayi berhasil menemukan payudara ibunya. Inilah awal hubungan menyusui antara bayi dan ibunya, yang akhirnya berkelanjutan dalam kehidupan ibu dan bayi (Sulistianingsih, 2020).

Berdasarkan hasil karakteristik responden, sebanyak $66.7 \%$ ibu bersalin berusia $19-29$ tahun dengan $48.5 \%$ adalah persalinan ke-2. Penelitian ini sejalan dengan pnelitian yang dilakukan Sukoco tahun 2021 dengan tema yang sama tentang inisiasi menyusu dini dimana usia ibu bersalin terbanyak pada usia 26-30 tahun. Ini menandakan sebagian besar responden berada dalam rentang puncak usia subur (Sukoco et al., 2021).

Pelaksanaan inisiasi menyusui dini (IMD) berdasarkan hasil penelitian yang telah dilakukan, dari 33 ibu bersalin menunjukkan sebanyak 28 ibu bersalin (84.8\%) dilakukan inisiasi menyusui dini, sedangkan 7 ibu bersalin (15.2\%) yang tidak melakukan inisiasi menyusui dini. Berdasarkan hasil penelitian, mayoritas ibu bersalin di Puskesmas Sawah Besar sudah di lakukan inisiasi menyusui dini (IMD). didukung pula oleh seluruh tenaga kesehatan yang ada di Puskesmas tersebut.

Hasil penelitian ini sejalan dengan bebrapa penelitian sebelumnya yang telah dilakukan. Pentingnya peran petugas sebagai care giver tehadap keberhasilan IMD Pembagian tugas dan kerjasama antar tim medis merupakan kunci keberhasilan dalam pelaksanaan IMD, sehingga ibu bersalin dan bayinya ecara maksimal mendapatkan hak mereka untuk IMD (Sukarti, I Gusti Ayu Trisna and Desak, 2020; Sulistianingsih, 2020; Sukoco et al., 2021).

Hubungan antara inisiasi menyusu dini dengan lamanya pelepasan plasenta pada penelitian ini menunjukkan hasil yang cukup berarti. Hasil menunjukkan ibu bersalin yang dilakukan inisiasi menyusu dini lama pengeluaran plasenta $92.8 \%<15$ menit nilai signifikansi pValue $=0,001 \quad(\alpha=0,05)$ dengan rata-rata waktu pengeluaran plasenta adalah 5.43 menit. Sedangkan ibu bersalin yang tidak dilakukan inisiasi menyusu dini menunjukkan hasil yang tidak signifikan pValue $=0,265 \quad(\alpha=0,05)$ dengan hasil lama pengeluaran plasenta $85.7 \%>15$ menit dan rata-rata waktu pengeluaran plasenta adalah 16.45 menit.

Hasil penelitian ini sejalan dengan beberapa penelitian sebelumnya yang menunjukkan bahwa ada hubungan yang signifikan antara inisiasi menyusui dini dengan kecepatan waktu pengeluaran plasenta (Nakao et al., 2008; sarli, 2017; Setiyani and Usnawati, 2021). Proses inisiasi menyusu dini akan merangsang pengeluaran oksitosin sehingga merangsang kontraksi uterus untuk segera mengeluarkan plasenta. Pelepasan dan pengeluaran plasenta ini ditunjang oleh hormon oksitosin uang merangsang kontraksi uterus. Hormon ini dapat dirangsang keluar secara alami karena bayi menyusu merangsang pengeluaran hormon oksitosin ini. oksitosin akan meningkat setelah kelahiran bayi, dimana ibu merasa bahagia melihat kelahiran bayinya. Sehingga produksi oksitosin dapat meningkat dan dapat mengurangi jumlah perdarahan postpartum (sarli, 2017; Satriani, 2021; Setiyani and Usnawati, 2021). (Widayati, Sulistianingsih and Saputri, 2020)

Inisiasi menyusu dini sangat penting dan harus dilakukan pada proses persalinan baik normal maupun cesar, terkecuali jika kondisi ibu atau bayi perlu penanganan lebih lanjut. Inisiasi menyusu dini juga tetap bisa dilakukan selama pandemic covid-19 saat ini dengan memperhatikan protocol kesehatan yang harus dilakukan untuk menjaga kesehatan ibu dan bayi. 
Vol 11 No 1 Bulan Januari | Page 144-148

\section{SIMPULAN}

Proses inisiasi menyusu dini sangat berpengaruh terhadap lama pelepasan plasenta, bounding attachment antara ibu dan bayi melalui skin to skin dan adanya hisapan pada puting susu dapat memicu pengeluran oksitosin alami sebagai hormon yang membantu dalam pelepasan plasenta sehingga palsenta dapat terlepas dengan mudah dan proses involusi uteri dapat berlangsung dengan baik untuk mencegah terjadinya perdarahan. Dukungan semua pihak mulai dari suami, keluarga, tenaga Kesehatan dan stakeholder yang lain sangat berpengaruh terhapap keberhasilan proses IMD.

\section{SARAN}

Bagi peneliti selanjutnya agar dapat memperluas variabel penelitian dan sampel yang lebih banyak. Serta melakukan penelitian yang bermanfaat bagi profesi, khususnya dapat mendukung program pemerintah agar dapat menekan angka kematian ibu dan bayi.

\section{DAFTAR PUSTAKA}

Abie, B. M. and Goshu, Y. A. (2019) 'Early initiation of breastfeeding and colostrum feeding among mothers of children aged less than 24 months in Debre Tabor, northwest Ethiopia: A crosssectional study', BMC Research Notes. BioMed Central, 12(1), pp. 1-6. doi: 10.1186/s13104019-4094-6.

BKKBN, BPS and Kemenkes RI (2018) 'Survei Demografi Kesehatan Indonesia', Usaid, pp. 1-606.

Fikawati, S., \& Syafiq, A. (2014) 'Kajian Implementasi dan Kebijakan Air Susu Ibu dan Inisiasi Menyusu Dini di Indonesia.', Makara Kesehatan, (14), pp. 17-24.

Kemenkes (2021) 'Laporan Kinerja Kementrian Kesehatan Tahun 2020', Kemenkes, pp. 1-209.

Nakao, Y. et al. (2008) 'Initiation of breastfeeding within 120 minutes after birth is associated with breastfeeding at four months among Japanese women: A self-administered questionnaire survey', International Breastfeeding Journal, 3, pp. 105-108. doi: 10.1186/1746-4358-3-1.

sarli, desi (2017) 'Hubungan Kadar Hormon Oksitosin Terhadap Lama Kala Iii Persalinan Serta Pengaruhnya Terhadap Jumlah Perdarahan Pada Ibu 2 Jam Postpartum', Jik- Jurnal Ilmu Kesehatan, 1(1), pp. 6-12. doi: 10.33757/jik.v1i1.20.

Satriani (2021) ASUHAN KEBIDANAN PASCA PERSALINAN DAN MENYUSUI. Edited by Yayuk Umaya. Malang: Ahlimedia book.

Setiyani, A. and Usnawati, N. (2021) 'Keberhasilan Inisiasi Menyusu Dini Dengan Involusi Rahim, Pelepasan Plasenta Dan Perdarahan Kala IV Persalinan', Jurnal Penelitian Kesehatan" SUARA ..., 12(1), pp. 341-344.

Smith, E. R. et al. (2017) 'Delayed breastfeeding initiation and infant survival : A systematic review and meta- analysis', pp. 1-16.

Sukarti, N. N., I Gusti Ayu Trisna, W. and Desak, Y. K. (2020) 'Hambatan Keberhasilan Pelaksanaan Inisiasi Menyusu Dini ( IMD ) pada Ibu Bersalin di Rumah Sakit Umum Pusat Sanglah Denpasar', Jurnal Ilmiah Kebidanan, 8(1), pp. 40-53.

Sukoco, B. et al. (2021) 'Peran Perawat dan Bidan terhadap Pelaksanaan Inisiasi Menyusu Dini (IMD)', Jurnal Keperawatan Silampari, 4(2), pp. 690-697. doi: 10.31539/jks.v4i2.1904.

Sulistianingsih, A. (2020) 'Faktor-Faktor yang Berpengaruh Terhadap Pelaksanaan Inisiasi Menyusui Dini Pada Ibu Bersalin', Jurnal Ilmiah Kesehatan, (1), p. 141.

Widayati, W., Sulistianingsih, A. and Saputri, N. (2020) 'Hubungan Peraturan Jam Kerja Dengan Keberhasilan', 37, pp. 4-7. 